\title{
Academic job satisfaction and motivation: findings from a nationwide study in Portuguese higher education
}

\author{
Maria de Lourdes Machado-Taylor ${ }^{\mathrm{a} *}$, Virgílio Meira Soares ${ }^{\mathrm{b}}$, Rui Brites ${ }^{\mathrm{c}}$, \\ José Brites Ferreira $^{\mathrm{d}}$, Minoo Farhangmehr ${ }^{\mathrm{e}}$, Odília Maria Rocha Gouveia ${ }^{\mathrm{a}}$ and \\ Marvin Peterson ${ }^{\mathrm{f}}$ \\ ${ }^{a}$ Center for Research in Higher Education Policies (CIPES), Matosinhos, Portugal, ${ }^{b}$ Faculty \\ of Sciences, University of Lisbon, Lisbon, Portugal; ${ }^{c}$ School of Economics and Management, \\ University of Lisbon, Lisbon, Portugal; ${ }^{d}$ School of Education and Social Sciences,

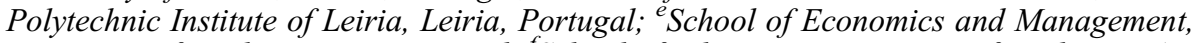 \\ University of Minho, Braga, Portugal; ${ }^{f}$ School of Education, University of Michigan, Ann \\ Arbor, MI, USA
}

\begin{abstract}
Academic staff is a key resource in higher education institutions (HEIs) and therefore has a major role in the achievement of the objectives of these institutions. Satisfied and well-motivated academic staff can build a national and international reputation for themselves and their institutions. Moreover, the performance of academic staff impacts student learning. In this context, the study of academic staff job satisfaction and motivation to perform their professional activities becomes crucial, especially as higher education is traversed by multiple changes. The purpose of this paper is to present and analyze the findings of a nationwide study on satisfaction and motivation of academics. All academics working in Portuguese HEIs were invited to complete a survey online. The data obtained from 4529 academics were extensively analyzed and findings are presented here along with their implications for HEIs in Portugal.
\end{abstract}

Keywords: job satisfaction; motivation; academic staff; higher education; Portuguese higher education

\section{Introduction}

Today's higher education institution (HEI) is an extremely complex social organization. One must examine a multitude of factors and their numerous interactions to even approach an understanding of HEI functions. One cannot minimize the confounding effects introduced by the human factor into social organizations. An important constituent group that contributes to the culture of an institution is the faculty or academic staff. The academic staff is a key resource for HEIs and therefore has a major role in the achievement of the objectives of the institution (Machado-Taylor, Meira Soares, and Gouveia 2010; Machado-Taylor et al. 2011).

Demands on academic staff in higher education (HE) have been increasing and may be expected to continue to increase. The centrality of the faculty role makes it a primary sculptor of institutional culture. The performance of academic staff as teachers and researchers determines much of the quality of the student satisfaction and impacts 
student learning and thus the contribution of HEIs to society. Therefore, the contribution of the academic staff to an HEI has implications for the quality of the institution (Enders 1999; Teichler 2009; Altbach 2003). Although job satisfaction is clearly an issue of importance to the professoriate, those outside academe pay it scant attention. In fact, for many casual observers, it is a moot point rendered meaningless by what is perceived to be the inordinately comfortable working conditions enjoyed by professors. Oversimplified and naive explanations of job satisfaction abound in all sectors of the workforce. Most typical is the mistaken belief that pay incentives alone create effective levels of motivation and thus overall job satisfaction. Serious research, however, has revealed that the concept of job satisfaction is a complex collection of variables that interact in myriad ways. Furthermore, the precise arrangement of these factors differs across segments of the job market. There are intrinsic variables related to personal growth and development and extrinsic factors associated with security in the work environment. There are global trends that impact professors and universities, notably accountability, massification, managerial controls, and deteriorating financial support (Hagedorn 2000; Stevens 2005; Addio, Eriksson, and Frijters 2007). There is also ample and somewhat obvious evidence that job satisfaction is related to employee motivation.

Job satisfaction is important in revitalizing staff motivation and in keeping their enthusiasm alive. Well-motivated academic staff can, with appropriate support, build a national and international reputation for themselves and the institution (Capelleras 2005) in the professional areas of research and publishing. Such a profile may impact the quality of an HEI. At the same time, institutions and their leaders who understand the intricate tapestry of organizational culture have an opportunity to tap into the multiple resources at their disposal and thus manage job satisfaction and employee motivation more effectively.

Although several studies have been examined around the world, little is known in the context of HE in Portugal. Certainly, the important area of academic staff job satisfaction is an under-researched subject in need of further discussion and documentation.

The project 'An Examination of Academic Job Satisfaction and Motivation in Portuguese Higher Education,' financed by the Foundation for Science and Technology, is being developed by the Center for Research in Higher Education Policies by a research team composed by seven members, including a consultant. ${ }^{1}$ This is a national study of academic staff satisfaction and motivation in the Portuguese context.

This paper aims to identify the career issues and their impacts on academic staff job satisfaction and motivation and to offer additional insights into relationships and strategies that can promote satisfaction and motivation. The main goal is to help Portuguese HEIs/researchers/professionals, etc., understand the parameters of job satisfaction and motivation in the professoriate.

This paper focuses on the findings from the initial analyses of the responses to a survey applied to academics from private and public HEIs. The questionnaire included questions about the academic career, motivation, and dimensions of satisfaction.

The following sections provide information about the framework of the research; key facts about Portuguese academic careers; methods; results by institutional type, gender, and age group; and a summary and initial conclusions.

\section{Framework of the research}

Research has revealed that the concept of job satisfaction is a complex collection of variables that interact in myriad ways. Moreover, according to Seifert and Umbach 
(2008), job satisfaction is an important factor as a predictor of the intent to remain in or leave the HE sector.

There is a belief that pecuniary factors are determinant to job satisfaction. However, salary alone is rarely the most important mover in faculty decisions to leave, as defended by Caplow and McGee (1958); Gartshore, Hibbard, and Stockard (1983); Johnsrud and Rosser (2002); Matier (1990); Smart (1990); Toombs and Marlier (1981; all as cited in Ambrose, Huston, and Norman 2005).

Verhaegen (2005) analyzed the recruitment and retention of academic talent as important factors for the success and competitiveness of a business school. The author verified that the most important factors for faculty from both recruitment and retention perspectives were academic freedom, research time, geographic location of the school, and opportunities for professional development. The less important factors for faculty were institutional factors, specifically the reputation of the school, innovativeness, and progressiveness of the school and international orientation (Table 1).

\section{Key facts about the Portuguese academic career}

Until the early 1970s, the Portuguese higher education (PHE) system was an elite system attended by a small portion of the population, mostly from the upper classes. The issue with the educational system was that it reproduced the dominant class. There was a situation of great inequality based on socioeconomic origin (Boudon 1973, as cited in Cabrito 2006). Thus, the HE system was not a democratic one, which was the consequence of the very political system itself. After 1974, as a consequence of the democratization of the country, the social demand for HE increased greatly (Cabrito 2006).

Today, PHE is organized into public and nonpublic HE. The legal framework of academic careers is quite different in public and private institutions. The government defines the size of the teaching staff and creates the rules for promotion in public institutions. In private institutions, the size of the academic body, career advancements, and remunerations are defined by the institutional decision-makers. The academic university and polytechnic staff differ in positions, career advancements, and remunerations. Mobility between the subsystems is possible; however, it is not very common. The rigidity of policies and regulations and the lack of a legal framework that supports any kind of mobility inhibit such moves (Meira Soares 2003).

Until 2009, the legal documents that regulate academic careers dated back to 1979 for the university academic staff and to 1985 for polytechnic academic staff. Recently, in 2009, academic careers in public HEIs were changed, although the main structures remain very similar. Not much is known about academic careers in private HEIs (private institutions follow private legislation, which makes their situations more difficult to analyze).

It is not the purpose of this work to delve into details, but the following aspects deserve mention:

(1) In the university sector, the career structure is reduced to three positions: auxiliary professor, assistant professor, and full professor. All of these positions can be filled only by candidates who have a $\mathrm{PhD}$ (a full professor also must have the Portuguese title Agregado $^{2}$ ), and all of the positions can be filled only after a public competition. In the case of auxiliary professor, the competition must be international. Invited academic staff members have fixed-term contracts 
Table 1. Categories and factors used in the survey.

\begin{tabular}{|c|c|}
\hline Categories & Factors \\
\hline The school's culture and values & $\begin{array}{l}\text { Academic freedom } \\
\text { Stimulating peer community } \\
\text { Participation in decision-making processes } \\
\text { Identification with school's mission and strategy } \\
\text { Availability of resources for new initiatives } \\
\text { Innovativeness and progressiveness of the school }\end{array}$ \\
\hline The school's reputation and position & $\begin{array}{l}\text { Reputation of the school in the academic community } \\
\text { Reputation of the school in the business community } \\
\text { Prestige/reputation of the department/discipline } \\
\text { Composition of the program portfolio } \\
\text { International orientation of the school } \\
\text { Partners in the school's network }\end{array}$ \\
\hline Conditions of employment & $\begin{array}{l}\text { Remuneration } \\
\text { Career opportunities } \\
\text { Job security } \\
\text { Nonfinancial reward systems } \\
\text { Resources for professional activities } \\
\text { Opportunities for sideline activities or additional jobs }\end{array}$ \\
\hline $\begin{array}{l}\text { Personal and professional } \\
\text { development }\end{array}$ & $\begin{array}{l}\text { Balance between work and life } \\
\text { Opportunities to work with people outside the school } \\
\text { Opportunities and facilities for family } \\
\text { Opportunities for personal growth and development } \\
\text { Opportunities for professional development } \\
\text { Opportunities to pursue cross-disciplinary scholarship }\end{array}$ \\
\hline Teaching climate & $\begin{array}{l}\text { Teaching time } \\
\text { Recognition of teaching achievements } \\
\text { Availability of teaching support } \\
\text { Availability of teaching facilities } \\
\text { Quality of students } \\
\text { Participation in executive education }\end{array}$ \\
\hline Research climate & $\begin{array}{l}\text { Research time } \\
\text { Recognition of research achievements } \\
\text { Financial resources for research } \\
\text { Availability of research support } \\
\text { Availability of research facilities } \\
\text { Research climate within the school }\end{array}$ \\
\hline Work environment & $\begin{array}{l}\text { Geographic location of the school } \\
\text { Need to speak local language } \\
\text { Professional opportunities for partner } \\
\text { Campus quality } \\
\text { Office quality } \\
\text { Competency of administrative staff and support } \\
\text { services }\end{array}$ \\
\hline
\end{tabular}

Source: Verhaegen (2005).

and may be exempted from the requirement to hold a $\mathrm{PhD}$. The tribunal that fills posts from public competitions must be staffed with a majority of external members. Additionally, an auxiliary professor who holds the required degrees and titles can compete for the post of full professor (which was not previously the case). These new legislations discourage in-breeding, favor internationalization, and encourage mobility. 
(2) In the polytechnic sector, career structures also have changed, and with the exception of one special case (described later), candidates to fill a post, also from public competition, must hold a $\mathrm{PhD}$. A new rank was introduced - Principal Coordinator Professor (Professor Coordenador Principal) - and a candidate must hold a PhD and the title of Agregado. The tribunals follow the same rules as the university sector regarding the number of external members. One exception exists here as well; given the more professional character of the sector, some people with exceptionally good CVs can be candidates for the professorship. They must hold the title of Specialist, which is awarded after public discussion of the $\mathrm{CV}$ and of a professional work presented by them. Invited staff also can exist but with some limitations.

(3) In the university sector and to a certain extent in the polytechnic sector, incentives can be considered for the development of scientific work, which confers staff conditions for promotion.

(4) In both sectors, periodic performance evaluations have been introduced and their results may have positive or negative impacts in staff careers.

These are some, but not all, of the main characteristics that we think must be mentioned to enrich the background context of our work.

Table 2 provides data on key characteristics of academic staff in Portuguese HEIs.

As given in Table 2, in 2009, 56.5\% of academics were men and $43.5 \%$ were women, or slightly more men than women. The vast majority of the academics worked in public HEIs (69.3\%). In PHE, $40.9 \%$ of the academic staff was teaching in public universities and $28.4 \%$ in polytechnic institutes; $19.1 \%$ of the academics were in private universities and only $11.7 \%$ in private polytechnic institutes. The

Table 2. Academic staff in Portuguese HEIs.

\begin{tabular}{lrrr}
\hline Academic staff & Year & $\mathrm{N}$ & $\%$ \\
\hline By gender & & & \\
Female & 2009 & 15,756 & 43.5 \\
Male & 2009 & 20,459 & 56.5 \\
By institutional type & & & \\
Public university & 2009 & 14,803 & 40.9 \\
Public polytechnic & 2009 & 10,289 & 28.4 \\
Private university & 2009 & 6899 & 19.1 \\
Private polytechnic & 2009 & 4224 & 11.7 \\
By age group & & & 6.3 \\
<30 & 2009 & 2274 & 29.0 \\
30-39 & 2009 & 10,518 & 34.0 \\
40-49 & 2009 & 12,296 & 22.4 \\
50-59 & 2009 & 8106 & 8.3 \\
60+ & 2009 & 3021 & 40.1 \\
By degree of education & & 14,205 & 26.0 \\
PhD & $2008^{\mathrm{a}}$ & 9472 & 31.7 \\
Master & 2008 & 11,217 & 0.7 \\
Licenciatura & 2008 & 261 & 0.0 \\
Bachelor & 2008 & 225 & \\
Other & 2008 & & \\
\hline
\end{tabular}

Sources: 2009: PORDATA (2011) and 2008: GPEARI (2010).

${ }^{\mathrm{a}}$ For this variable, the most recent data are available from 2008. 
vast majority of the academics (63\%) were between the ages of 30 and 49 . Academics younger than 30 and over 60 were less frequent $(6.3 \%$ and $8.3 \%)$. With respect to the degree of education, the highest proportion of academics had a $\mathrm{PhD}(40.1 \%), 31.7 \%$ had a Licenciatura, and $26.8 \%$ had a master's degree. The other situations (bachelor's degree and others) are residual.

\section{Method: the survey}

Before the distribution of the questionnaire, the research team held three focus groups to determine the factors of satisfaction/dissatisfaction and motivation/demotivation of academics. The information gathered was used in the construction of the questionnaire. Thus, the survey resulted from the review of the literature on this theme and from the concerns expressed by faculty members/participants in the focus groups. The survey was posted online and all university faculty members, including all subgroups (professor, researcher, part-time, full-time, etc.), of all types of Portuguese HEIs (public-private and university-polytechnic) were invited to participate.

The questionnaire was available to all Portuguese academics on the website http:// questionarios.ua.pt/index.php?sid=19766\&lang=pt with the address sent to potential participants. The survey includes questions about the motivation of the academics, their general satisfaction, and about the degree of satisfaction with a variety of aspects related to the academic profession and to the HEI where academics taught (the satisfaction dimensions).

The dimensions of satisfaction considered in this study were: teaching climate, management of the institution/department/unit, colleagues, nonacademic staff (administrative staff, technical, and laboratorial staff), physical work environment, conditions of employment, personal and professional development, institutional culture and values, institutional prestige, research climate, and general satisfaction, as given in Table 3 .

All of the academics were invited to complete the online survey. A total of 4529 academics participated in the study.

All quantitative data collected were placed in a database. The database and its subsequent analyses were performed using the Statistical Package for the Social Sciences. Statistical procedures conducted for this paper included descriptive statistics, custom tables, one-way ANOVA tests, independent-sample $t$-tests, and synthetic indices. When three or more groups were compared, we used ANOVA and if significant, we use a multiple comparison test to the post. When the variances are not homogeneous, we used the GAMMES-HOWELL. The construction of the analysis dimensions (synthetic indexes) from the information collected from indicators, necessarily fragmented, should be driven by theory. In this sense, as highlighted by Saris (2010), many concepts are measured using multiple indicators. Construction of the analysis adhered to the following criteria: (1) items must be evaluated on quality and should be equivalent to those from other countries (i.e. in translation, retroversion, and expert analysis); (2) weights should be chosen for calculation of composite scores; and (3) the quality of the composite scores must be determined.

From this perspective, the construction of synthetic indices should be completed not by using the simple arithmetic average of the indicators but with a principal component analysis with a single component. The factorial scores are, in this case, the individual scores in the index. Thus: (1) the quality of the items must first be assessed using Cronbach's alpha; (2) the process ensures the weighting of indicators; and (3) the explained variance 
Table 3. Dimensions of satisfaction.

Teaching climate

Management of the institution/ department/unit

\section{Colleagues}

Nonacademic staff (administrative staff, technical and laboratorial staff)

Physical work environment
Distribution of teaching service for teachers of one's department/organizational unit

Recognition from one's peers

Teaching facilities (e.g. classrooms and laboratories)

Training of students

Results of one's work as a faculty member

Degree of autonomy in one's teaching practice

Class sizes

Organization of schedules

Those in top management positions in one's institution

Those in top management positions in one's department/organizational unit

Communication with managers

Management response to faculty needs

Ability of those in management to innovate

Time that those in management take to respond to the needs of faculty

Skills of faculty of one's department/organizational unit

Scientific quality of the faculty of one's department/ organizational unit compared with faculty of other similar institutions

Pedagogic quality of the faculty of one's department/ organizational unit compared with faculty of other similar institutions

Interaction between faculty members of different courses

Cooperation with colleagues from different departments/units

Openness to change shown by faculty of one's department/organizational unit

Cooperation of administrative staff in one's institution

Cooperation of technical/laboratory staff in one's institution

Performance of nonacademic staff in one's institution

Adequacy of the number of nonacademic staff for the amount of existing work

Quality of the office

Adequacy of laboratory equipment for one's needs

Adequacy of computer facilities for one's needs

Adequacy of reviews and books in one's institution to perform one's work

Food service (restaurant/bar/canteen)

Cleanliness of the institution

Equipment available to faculty and their families (e.g. gym, nursery, and living spaces)

Existence of an area in which to monitor the students (e.g. ask questions)

The fact that one must share an office

Existence of meeting space

Size of classrooms

Availability of parking for faculty 
Table 3. Continued.

\begin{tabular}{|c|c|}
\hline Conditions of employment & $\begin{array}{l}\text { One's remuneration } \\
\text { Career opportunities } \\
\text { Job security }\end{array}$ \\
\hline \multirow[t]{3}{*}{ Personnel and professional development } & $\begin{array}{l}\text { Conditions one must balance between work and } \\
\text { family life }\end{array}$ \\
\hline & Conditions for personal development \\
\hline & Conditions for professional development \\
\hline \multirow[t]{3}{*}{ Institutional culture and values } & Academic freedom \\
\hline & $\begin{array}{l}\text { Participation of faculty of one's institution in } \\
\text { decision-making processes }\end{array}$ \\
\hline & Ability to innovate in one's institution \\
\hline \multirow[t]{4}{*}{ Institutional prestige } & Prestige of institution \\
\hline & International partners of one's institution \\
\hline & National partners of one's institution \\
\hline & Efforts of one's institution to improve its image \\
\hline \multirow[t]{8}{*}{ Research climate } & Time to do research \\
\hline & Recognition by the institution of one's research work \\
\hline & Financial resources to do research \\
\hline & Logistical conditions to do research \\
\hline & One's research outputs \\
\hline & Degree of internationalization of one's research work \\
\hline & Opportunities to do research \\
\hline & One's number of publications/presentations \\
\hline \multirow[t]{5}{*}{ General satisfaction } & One's job \\
\hline & One's institution \\
\hline & Opportunity to update knowledge \\
\hline & Adequacy of one's skills for one's teaching practice \\
\hline & Social prestige of one's job \\
\hline
\end{tabular}

quantifies the quality of the index. In support of this procedure, it should also be noted that the index can contain indicators with different measurement scales.

\section{Results by institutional type, gender, and age group}

\section{Characterization of the respondents by institutional type, age group, and gender}

Respondents can be briefly characterized by institutional type, age group, and gender.

Most survey participants worked in public HEIs (79\%; universities and polytechnic institutes had $42.8 \%$ and $36.2 \%$, respectively). Only $13.2 \%$ of the respondents pursued their academic professions in private universities and $7.8 \%$ in private polytechnic institutes.

Comparing these numbers with those that relate to the population of all Portuguese academics (Figure 2), we see that about $70 \%$ of the academics belong to public HE and only $30 \%$ belong to private HE. About $41 \%$ of the academics work at public universities and $28.4 \%$ teach in public polytechnic institutes. Among the academics in private HE, $19.1 \%$ belong to the university subsystem and only $11.7 \%$ to polytechnic institutes.

With regard to age groups, respondents were concentrated in age groups 41-50 years $(38.2 \%), 31-40$ years $(28 \%)$, and $51-60$ years $(23.7 \%)$. On average, the age of respondents was 45 years and the mode was 44 years.

Data about the population were similar to those for the numbers of respondents. The age groups for which values are high were 40-49 years (34\%), 30-39 years (29\%), and 
$50-59$ years $(22.4 \%)$. The age groups for younger $(<30$ years) and older $(\geq 60$ years) academics are those with less weight (6.3\% and $8.3 \%$, respectively).

The distribution of respondents by gender was $50.7 \%$ male and $49.3 \%$ female.

The genders of the total academics in PHE were verified at slightly more males $(56.5 \%)$ than females $(43.5 \%)$. This shows that our sample has relatively more female respondents than the total proportion of academics in PHE.

\section{General satisfaction by institutional type, age groups, and gender}

With regard to general satisfaction, the academics were satisfied, with the mean $=6.30$ on a scale from 0 to 10 ('extremely dissatisfied' to 'extremely satisfied'). However, general satisfaction was not very high (i.e. was not close to point 10 of the scale) (Table 4).

General satisfaction was higher (i.e. above the average with mean $=0$ ) for those in private institutions, and within this group, the general satisfaction was higher for those in private universities than for the academics in private polytechnic institutes. In public $\mathrm{HE}$, general satisfaction was lower in public universities. Public polytechnic institutes had a value around the average value $(-0.031)$. Using the one-way ANOVA test with a significance level of 0.05 , it is clear that these differences in the satisfaction of academics in various institutional types are statistically significant $[F(3)=18.676 ; p=.000]$.

In terms of satisfaction by age group, we found that academics aged between 41 and 50 years and between 51 and 60 years were those who were least satisfied and had the lowest values $(-0.68$ and -0.40 , respectively). Academics aged 30 years or less reported a higher degree of satisfaction (0.503). Following these academics were those aged 61 years or more and those aged between 31 and 40 years, also with significant degrees of satisfaction ( 0.100 and 0.053 , respectively). Overall, academics at the beginnings of their careers and those who were older (aged 61 years or more) indicated greater satisfaction. Using the one-way ANOVA test at a significance level

Table 4. General satisfaction by institutional type, age and gender.

\begin{tabular}{llrcccc}
\hline & & \multicolumn{5}{c}{ General satisfaction } \\
\cline { 3 - 7 } & & $N$ & Minimum & Maximum & Mean & $\begin{array}{c}\text { Standard } \\
\text { deviation }\end{array}$ \\
\hline Institutional type & Public university & 1377 & 0 & 10 & $6.1^{* *}$ & 1.87 \\
& Public polytechnic & 1167 & 0 & 10 & 6.3 & 1.86 \\
& Private university & 425 & 0 & 10 & $6.9^{* *}$ & 2.00 \\
& Private polytechnic & 252 & 1 & 10 & $6.8^{* *}$ & 1.92 \\
Age & Total & 14221 & 0 & 10 & $6.3^{* *}$ & 1.90 \\
& Under 30 years & 1 & 10 & $7.3^{* *}$ & 1.71 \\
& 31-40 years & 877 & 0 & 10 & $6.4^{* *}$ & 1.83 \\
& 41-50 years & 1198 & 0 & 10 & $6.2^{* *}$ & 1.93 \\
& 51-60 years & 743 & 0 & 10 & $6.2^{* *}$ & 1.87 \\
& $>60$ years & 176 & 0 & 10 & $6.5^{*}$ & 2.15 \\
& Total & 3137 & 0 & 10 & 6.3 & 1.90 \\
& Female & 1587 & 0 & 10 & 6.3 & 1.83 \\
& Male & 1629 & 0 & 10 & 6.3 & 1.97 \\
& Total & 3216 & 0 & 10 & 6.3 & 1.90 \\
\hline
\end{tabular}

$*_{p}<.005$.

$* * p<.001$. 
of 0.05 , it is clear that these differences in satisfaction among academics in various age groups were statistically significant $[F(4)=10.911 ; p=.000]$. The largest difference verified was among academics aged 30 years or less and all of the other age groups.

Most studies have shown that age is associated with academic job satisfaction, and older individuals generally show greater satisfaction with their work (Holden and Black 1996; Near, Rice, and Hunt 1978; Oshagbemi 1997, 2003, all as cited in Platsidou and Diamantopoulou 2009).

In the Portuguese case, we noticed some nuances, including the fact that academics aged less than 30 years show high satisfaction, possibly because the early-career academics feel a big difference when comparing their recent careers in HE with other professions that endure poor working conditions in the country. The dissatisfaction of academics aged 41-60 may be attributed to the change in laws and the working and economic conditions that constrain their promotions, contrary to their expectations when they joined academia.

General satisfaction of academics was similar for women and men, but men seemed to be slightly more satisfied.

However, using the independent-samples $t$-test at a significance level of 0.05 , we found that the difference between women and men was not statistically significant $[t(2998.834)=$ $-0.186 ; p>.05]$. This result coincides with results of other studies in other countries. Authors such as Ward and Sloane (2000), Santhapparaj and Alam (2005), and Stevens (2005) found that women and men expressed similar levels of satisfaction.

\section{Satisfaction dimensions}

The dimensions of satisfaction considered in this study were chosen after an extensive review of the literature and the analysis of questionnaires developed by experts in the area of academic job satisfaction and motivation. These dimensions are: teaching climate; management of the institution/department/unit; colleagues; nonacademic staff (administrative and technical and laboratorial staff); physical work environment; conditions of employment; personal and professional development; institutional culture and values; institutional prestige and research climate.

Our analysis of the synthetic indexes for each dimension of satisfaction verified that the higher values are in the dimensions of nonacademic staff (administrative and technical and laboratorial staff; mean $=6.3)$, teaching climate $($ mean $=6.0)$, and colleagues (mean $=6.0)$. On the contrary, the dimensions for which academics expressed less satisfaction were research climate $($ mean $=4.2)$ and conditions of employment $($ mean $=4.3)($ Table 5).

The results are consistent with the conclusions of Ssesanga and Garrett (2005) that academics were relatively satisfied with coworker behavior and intrinsic factors of teaching. Ward and Sloane (2000) found that academics were most satisfied with the opportunity to use their own initiative, with relationships with their colleagues, and with the actual work; they were least satisfied with promotion prospects and salary. In the present study, academics were least satisfied with conditions of employment and research climate.

The analysis of academics' satisfaction with the dimensions of nonacademic staff, physical work environment, conditions of employment, and institutional culture and values by gender, using the independent-samples $t$-test at a significance level of 0.05 , we verified that the difference in satisfaction between the genders for these aspects was not statistically significant. 
Table 5. Satisfaction dimensions (synthetic index).

\begin{tabular}{|c|c|c|c|c|c|}
\hline & $\begin{array}{l}\text { Valid } \\
N\end{array}$ & Minimum & Maximum & Mean & $\begin{array}{l}\text { Standard } \\
\text { deviation }\end{array}$ \\
\hline Satisfaction with teaching climate & 3870 & 0 & 10 & 6.1 & 1.53 \\
\hline $\begin{array}{l}\text { Satisfaction with management of the } \\
\text { institution/department/unit }\end{array}$ & 3667 & 0 & 10 & 5.3 & 2.52 \\
\hline Satisfaction with colleagues & 3709 & 0 & 10 & 6.1 & 1.94 \\
\hline $\begin{array}{l}\text { Satisfaction with physical work } \\
\text { environment }\end{array}$ & 1729 & 0 & 10 & 5.3 & 1.95 \\
\hline $\begin{array}{l}\text { Satisfaction with nonacademic staff } \\
\text { (administrative staff, technical, and } \\
\text { laboratorial staff) }\end{array}$ & 3059 & 0 & 10 & 6.4 & 1.94 \\
\hline $\begin{array}{l}\text { Satisfaction with conditions of } \\
\text { employment }\end{array}$ & 3919 & 0 & 10 & 4.3 & 2.41 \\
\hline $\begin{array}{l}\text { Satisfaction with personal and } \\
\text { professional development }\end{array}$ & 3952 & 0 & 10 & 5.3 & 2.49 \\
\hline $\begin{array}{l}\text { Satisfaction with institution: culture and } \\
\text { values }\end{array}$ & 3849 & 0 & 10 & 5.7 & 2.20 \\
\hline Satisfaction with institution: prestige & 3683 & 0 & 10 & 5.8 & 2.28 \\
\hline $\begin{array}{l}\text { Satisfaction with research (only } \\
\text { researchers } N=3327 \text { ) }\end{array}$ & 2911 & 0 & 10 & 4.2 & 2.04 \\
\hline
\end{tabular}

With respect to the dimensions of teaching climate, management, colleagues, personnel and professional development, institutional prestige, and research climate, and the degree of satisfaction with these aspects, using the same test, we concluded that there are statistically significant differences between the genders.

Males $($ mean $=6.1482)$ were more satisfied than females $($ mean $=6.0121)$ with teaching climate; females $($ mean $=5.4210)$ were more satisfied than males (mean $=$ $5.1321)$ with management; females $($ mean $=6.1826)$ revealed more satisfaction than males $($ mean $=5.9532)$ with colleagues; males expressed more satisfaction (mean = 5.5500) than females (mean $=5.1712$ ) with personal and professional development; females $($ mean $=5.9437)$ revealed more satisfaction than males $($ mean $=5.6011)$ with institutional prestige; and males $($ mean $=4.4818)$ were more satisfied than females (mean $=4.0807)$ with research climate.

With respect to satisfaction with physical work environment by age groups, there were no statistically significant differences $[F(4)=1.178 ; p=.319]$. The differences in satisfaction with teaching climate by age group were clear. Using the one-way ANOVA test at a significance level of 0.05 , it was evident that these differences in satisfaction among academics in various age groups were statistically significant $[F(4)=5.114 ; p=.000]$. The largest difference verified was among academics aged 30 years or less (the most satisfied; mean $=0.333$ ) and the age group $41-50$ years (mean $=-0.024)$; for respondents aged 51-60 years the mean was -0.018 , and for the 31-40 group, the mean was 0.053 . Academics aged 61 years or more years were the second most satisfied group of academics for the teaching climate dimension (mean $=0.144)$.

With respect to differences in satisfaction with colleagues by age group, differences in satisfaction were statistically significant $[F(4)=6.650 ; p=.000]$. The largest difference verified was among academics aged 30 years or less (the most satisfied; mean = 0.438 ) and all the other age groups: for those aged $31-40$ years, the mean was 0.027 ; for the $41-50$ year group, the mean was -0.0004 ; for those aged $\geq 61$ years, the mean was 
-0.040 ; and for those in the 51-60 year group, the mean was -0.052 . Thus, it seems that older academics were more dissatisfied with colleagues.

Differences in satisfaction with the nonacademic staff dimension by age group were statistically significant $[F(4)=7.595 ; p=.000]$. The largest difference confirmed was among academics aged 30 years or less (the most satisfied; mean $=0.450$ ) and all the other age groups: for those aged $\geq 61$ years, the mean was 0.155 ; for the $31-40$ group, the mean was 0.035 ; for those aged $51-60$ years, the mean was -0.037 ; and for the 41-50 year group, the mean was -0.061 . Therefore, academics aged between 41 and 60 years were the most dissatisfied with nonacademic staff. Younger academics (aged $\leq 30$ years) were the most satisfied with this dimension of the academic profession.

Differences in satisfaction with the personal and professional development dimension by age group were statistically significant $[F(4)=11.817 ; p=.000]$. The largest difference confirmed was among academics aged 30 years or less and those aged 61 years or more (the most satisfied; means $=0.354$ and 0.347 , respectively) and academic staff aged between 31 and 60 years. Academics who were most dissatisfied were those aged between 41 and 50 years with a value below the average (mean= $-0.079)$.

With respect to satisfaction with the research climate dimension by age group, there were statistically significant differences $[F(4)=4.791 ; p=.001]$. The largest difference confirmed was among academics aged 61 years or more (the most satisfied with research climate; mean $=0.332$ ) and those academics aged between 41 and 50 years (the most dissatisfied with research climate; mean $=-0.045$ ).

Regarding satisfaction with the management of the institution/department/unit dimension by age group, the group of academics that was most satisfied were those aged 30 years or less $($ mean $=0.526)$. The most dissatisfied academics with this aspect were those aged between 41 years and more, with negative means: 41-50 years $($ mean $=-0.062) ; 51-60$ years $($ mean $=-0.048)$; and $\geq 61$ years $($ mean $=-0.069)$.

The one-way ANOVA test revealed statistically significant differences $[F(4)=$ $11.363 ; p=.000$ ] between satisfaction of academics aged 30 years or less (the most satisfied) and the satisfaction of all the other academics (aged $>31$ years). In addition, academics aged 31-40 years expressed more satisfaction than those aged between 41 and 50 years.

With respect to satisfaction with the conditions of employment dimension by age group, the academics aged 31-40 years and 41-50 years were the most dissatisfied (means were -0.066 and -0.060 , respectively). The most satisfied were the older academics: those aged $51-60$ years $($ mean $=0.147)$ and those aged 61 years or more (mean $=0.251$ ). The one-way ANOVA test revealed statistically significant differences $[F(4)$ $=8.803 ; p=.000]$ between satisfaction of academics aged $31-40$ years and $41-50$ years (less satisfaction) than those aged 51 or more years (more satisfaction).

With regard to satisfaction with the institutional culture and values dimension by age group, academics most satisfied were those aged 30 years or less (mean $=0.416$ ), followed by those aged $31-40$ years $($ mean $=0.035)$. Academics aged $41-50$ (mean $=-0.024), 51-60$ years $($ mean $=-0.020)$, and 61 or more years $($ mean $=-0.003)$ were dissatisfied.

The one-way ANOVA test revealed statistically significant differences $[F(4)=$ $6.021 ; p=0.000$ ] between the satisfaction of academics aged 30 years or less (expressed more satisfaction) and that of all of the other academics aged 31 years or more (expressed less satisfaction). 
Finally, for satisfaction with the institutional prestige dimension by age group, the most satisfied academics were those aged 30 years or less (mean $=0.333$ ); the most dissatisfied were those aged $41-50$ years $($ mean $=-0.058)$.

The one-way ANOVA test revealed statistically significant differences $[F(4)=$ $4.760 ; p=.001$ ] between satisfaction of academics aged 30 years or less (expressed more satisfaction) and academics aged $31-40$ years, 41-50 years, and 51-60 years (indicated less satisfaction or dissatisfaction).

Given the above, the analysis of satisfaction dimensions by institutional type revealed some important details.

The differences in satisfaction with the teaching climate dimension by institutional type were clear. The one-way ANOVA test at a significance level of 0.05 , revealed statistically significant differences in satisfaction with this aspect by institutional type $[F(3)=35.611 ; p$ $=.000]$. There is a huge difference among academics from public HEIs, who had negative means and were thus more dissatisfied $(-0.120$ for public universities and -0.006 for public polytechnic institutes) and academic staff from private HEIs, who were more satisfied ( 0.358 for private universities and 0.366 for private polytechnic institutes).

The one-way ANOVA test at a significance level of 0.05 revealed statistically significant differences in satisfaction with the management dimension by institutional type $[F(3)=37.964 ; p=.000]$. There was a large difference among academics from public universities (mean $=-0.215$; more dissatisfied) and academics from private universities $($ mean $=0.276)$ and private polytechnic institutes (mean $=0.265$; more satisfied). There were no significant differences among those from public polytechnics.

With respect to satisfaction with the dimension personnel and professional development by institutional type, academics in public HE (public polytechnic institutes and public universities) were the most dissatisfied, with values below the average $(-0.035$ for public polytechnic institutes and -0.031 for public universities). The more satisfied academics were those in private universities (mean $=0.241)$. This difference is statistically significant $[F(3)=10.062 ; p=.000]$.

With regard to satisfaction with the institutional prestige dimension, using the oneway ANOVA test at a significance level of 0.05 , it was evident that there are statistically significant differences $[F(3)=9.948 ; p=.000]$. Academics at public polytechnic institutes were the most dissatisfied (mean $=-0.089$ ), followed by those at public universities $($ mean $=0.000)$; the most satisfied are those who worked at private universities $($ mean $=0.230)$.

Regarding satisfaction with the colleagues dimension by institutional type, the more satisfied academics were those at private universities (mean $=0.408)$, followed by those at private polytechnic institutes $($ mean $=0.331)$. The most dissatisfied academics with this aspect were those at public universities (mean $=-0.137$ ), followed by those at public polytechnic institutes (mean $=-0.014)$.

The one-way ANOVA test showed statistically significant differences $[F(3)=$ $38.316 ; p=.000]$ between the satisfaction of academics at private universities and private polytechnic institutes (the most satisfied) and the satisfaction of the academic staff working at public universities and public polytechnic institutes (the most dissatisfied).

Academics who were more satisfied with the nonacademic staff dimension were those at private universities (mean $=0.508$ ), followed by those at private polytechnics (mean $=0.448)$. The most dissatisfied academics with this aspect were those at public universities (mean $=-0.172$ ), followed by those at public polytechnic institutes (mean $=-0.052)$. 
The one-way ANOVA test proved that there were statistically significant differences $[F(3)=54.496 ; p=.000]$ between satisfaction of academics at private universities and private polytechnic institutes (the most satisfied) that those who worked at public universities and public polytechnic institutes (the most dissatisfied).

Academics who were more satisfied with the physical work environment dimension were those at private universities (mean $=0.300)$, followed by those at private polytechnic institutes $($ mean $=0.208)$. Academics from public universities were dissatisfied (mean $=-0.149)$. The value for academics at public polytechnic institutes was close to the average $($ mean $=0.053)$.

The one-way ANOVA test confirmed that there are statistically significant differences $[F(3)=10.815 ; p=.000]$ between the satisfaction of academics at public universities (less satisfied) and those who worked at public polytechnic institutes, private universities, and private polytechnic institutes (more satisfied).

With respect to satisfaction with the conditions of employment dimension, academics who were more satisfied with this aspect were those who taught at private universities (mean $=0.232)$. Academics at public polytechnic institutes and at public universities showed negative values $(-0.055$ and -0.024 , respectively). Thus, academics at public polytechnic institutes were the most dissatisfied with conditions of employment.

The one-way ANOVA test confirmed that there are statistically significant differences $[F(3)=9.314 ; p=.000]$ between the satisfaction of academics at private universities (more satisfied) and those at public universities and public polytechnic institutes (less satisfied).

Regarding satisfaction with institutional culture and values, academics who were more satisfied with this aspect were those who taught at private universities (mean = $0.297)$, followed by those at private polytechnic institutes (mean $=0.258$ ). Academics at public universities and public polytechnic institutes expressed negative values $(-0.105$ and -0.010 , respectively).

The one-way ANOVA test validated statistically significant differences $[F(3)=$ 21.983; $p=.000$ ] between satisfaction of academics at private HEIs (universities and polytechnic institutes; satisfied) and those at public HEIs (universities and polytechnic institutes; dissatisfied).

Academics who were more satisfied with the research climate dimension were those who taught at private universities $($ mean $=0.184$ ), followed by those who worked at public universities $($ mean $=0.150)$. Academics who were more dissatisfied were those at public polytechnic institutes (mean $=-0.211$ ), followed by those at private polytechnic institutes (mean $=-0.075$ ). The one-way ANOVA test showed statistically significant differences $[F(3)=24.434 ; p=.000]$ between the satisfaction of academics at universities (public and private; satisfied) and those at public polytechnic institutes (dissatisfied).

Overall, Portuguese academics are not very satisfied. These findings reflect those of Portuguese changing academic profession (CAP) respondents. The CAP findings placed Portugal among the countries with lower levels of overall satisfaction. Only South Africa showed a lower level of overall satisfaction among academics (Dias et al. 2012).

\section{Motivation by institutional type, age groups, and gender}

Academics were asked about their motivation (i) to teach; (ii) to do research; (ii) to serve the community; (iv) to participate in the governing bodies; (v) to work in their present institution; and finally (vi) to remain as a faculty member in HE. 
Table 6. Motivation (synthetic index).

\begin{tabular}{lcccc}
\hline & Mean & Minimum & Maximum & Standard deviation \\
Motivation & 7.0 & 0.00 & 10.00 & 1.78 \\
\hline
\end{tabular}

Considering a scale from 0 to 10 (extremely demotivated to extremely motivated), the present research verified that academics in PHE are motivated (mean $=7$ ). However, motivation was not very high (i.e. not close to point 10 of the scale; Table 6).

With respect to job motivation by institutional type, custom tables revealed that academics in private $\mathrm{HE}$ were more motivated in the academic profession (values for private universities and private polytechnic institutes were above the mean [0]; 0.320 and 0.281 , respectively). The more demotivated academics were those who worked at public universities $(-0.177)$, followed by those at public polytechnic institutes $(0.052)$.

The one-way ANOVA test, at a significance level of 0.05 , showed that these differences in motivation among academics at different institutional types were statistically significant $[F(3)=36.017 ; p=.000]$, except for the difference between motivation of the academic staff at private polytechnic institutes and private universities, which was not statistically significant (Figure 1).

In the analysis of job motivation by age groups, academics aged between 51 and 60 years and between 41 and 50 years were those who were least motivated, with the lowest values (below the average of 0 at -0.043 and -0.024 , respectively). Academics aged 30 years or less were the most motivated (0.444). Those aged $31-40$ years and academics aged 61 years or more were next, with a value of 0.025 .

The one-way ANOVA test, at a significance level of 0.05 , confirmed that these differences were statistically significant $[F(4)=7.157 ; p=.000]$. The largest difference verified was among academics aged less than 30 years and all of the other age groups (Figure 2).

Results showed that women seem to be more motivated than men in PHE (values were 0.066 for women and -0.051 for men). The test independent-samples $t$-test, at

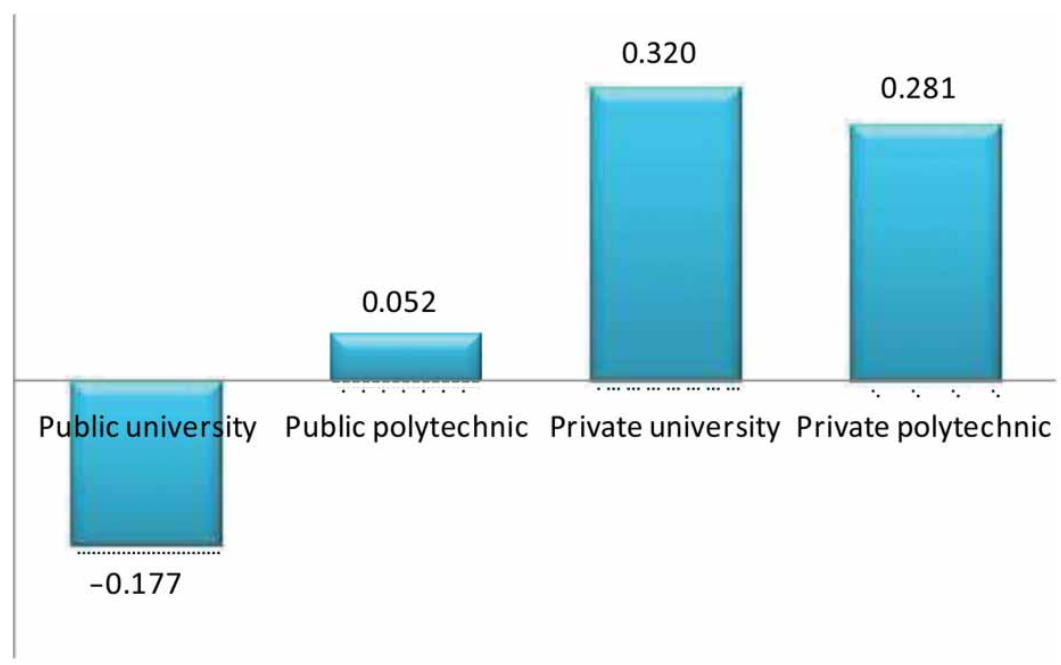

Figure 1. Job motivation by institutional type. 


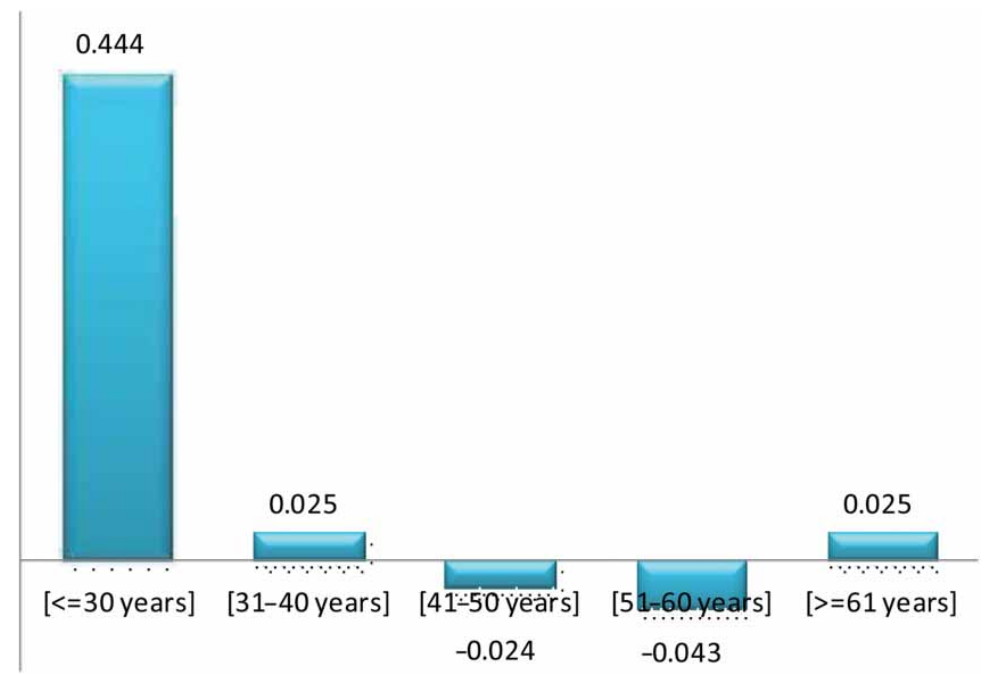

Figure 2. Job motivation by age group.

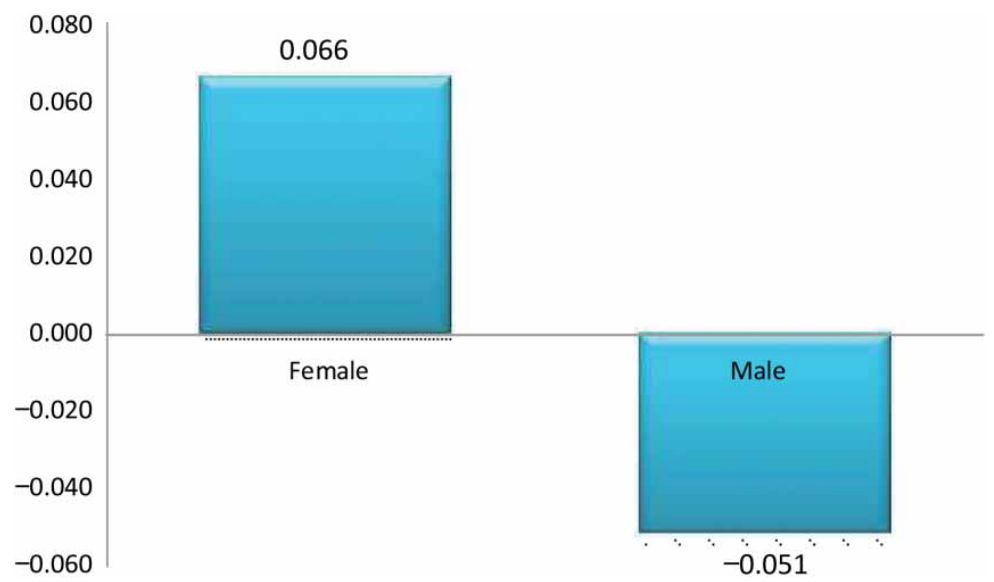

Figure 3. Job motivation by gender.

a significance level of 0.05 , revealed that the difference between the genders was statistically significant $[t(3001.049)=3.262 ; p<.05$; Figure 3$]$.

\section{Summary and preliminary conclusions}

On a scale from 0 to 10 (extremely dissatisfied to extremely satisfied), Portuguese academics were satisfied with their academic professions $($ mean $=6.30)$ but not very satisfied in general. General satisfaction was higher for those at private institutions, and within this group, the value was higher at private universities than for those at private polytechnic institutes. In public HE, general satisfaction was lower at public universities. Regarding general satisfaction by age group, overall, academics who 
were at the beginning of their careers and those who were older (aged 61 years or more) indicated greater satisfaction. With respect to general satisfaction by gender, the difference between females and males was not statistically significant. This result is similar to those from other studies conducted in other countries. Authors such as Ward and Sloane (2000), Santhapparaj and Alam (2005), and Stevens (2005) found that males and females expressed similar levels of satisfaction.

Academic staff expressed more satisfaction with nonacademic staff (administrative staff and technical and laboratorial staff), teaching climate, and colleagues. On the contrary, academics revealed less satisfaction with research climate and conditions of employment. These results were similar to the conclusions of Ssesanga and Garrett (2005) that academics are relatively satisfied with coworker behavior and intrinsic factors of teaching. Ward and Sloane (2000) found that academics were most satisfied with the opportunity to use their own initiative, with the relationship with their colleagues, and with the actual work; the academics were least satisfied with promotion prospects and salary.

Academics were motivated (mean $=7$ ), but motivation was not very high. Academics in private HE were more motivated. The more demotivated academics were those who worked at public universities, followed by those at public polytechnic institutes. Academics aged 30 years or less were the most motivated, followed by the other age groups (31-40 years and academics aged 61 years or more). Females seem to be more motivated than males at Portuguese HEIs.

The findings of this research indicate that Portuguese academics are not very highly satisfied or even motivated. Results concur with those gathered from the CAP Project (Dias et al. 2012).

These results must be carefully examined by institutional leaders and policy-makers in Portugal to promote academic satisfaction, particularly in the areas with which academics are dissatisfied, which were mainly with conditions of employment and research climate. Moreover, particular attention also seems to be needed in public HEIs with academics aged in their $40 \mathrm{~s}$ and $60 \mathrm{~s}$.

Future research could be conducted to determine the state of satisfaction and motivation of faculty in Portugal, in 5 or 10 years, to conduct a diachronic study and to check improvements enabled by the present study and aspects/dimensions of satisfaction/ motivation to improve. Moreover, a comparative study on faculty satisfaction and motivation in various countries could provide fundamental information to improve human resource management at HEIs and, therefore, to create satisfaction, to improve the performance of the academic staff, and to retain and attract academic talent.

Institutional leadership has an important role in the creation of job satisfaction by identifying the factors that cause low job satisfaction and dissatisfaction and using these data to identify ways to improve. All of this is crucial because 'job satisfaction has significant impact on employee commitment to the organizations, job performance, and motivation. At the same time, employees with high job satisfaction would lead to lower turnover and absenteeism' (Noordin and Jusoff 2009, 125). According to Silva (1998), today's market requires permanent, ongoing evaluation of competitive ability. The importance of the human factor and its involvement in the objectives of the organization becomes clear in this context.

\section{Acknowledgments}

The article was prepared with the financial aid of the Foundation for Science and Technology. 


\section{Notes}

1. The research team is composed of Virgílio Meira Soares, Maria de Lourdes Machado, José Brites Ferreira, Rui Brites, Minoo Farhangmerh, Odília Gouveia, and Marvin Peterson.

2. Postdoctoral degree granted to those who, before an examination board composed of Full Professors selected at national/international level, during two days of formal open examination, present and defend their work.

\section{References}

Addio, A. C., T. Eriksson, and P. Frijters. 2007. "An Analysis of the Determinants of Job Satisfaction when Individuals' Baseline Satisfaction Levels May Differ." Applied Economics 39 (19): 2413-23.

Altbach, P. G. ed. 2003. The Decline of the GURU: The Academic Profession in the Third World. New York: Palgrave MacMillan.

Ambrose, S., T. Huston, and M. A. Norman. 2005. "Qualitative Method for Assessing Faculty Satisfaction." Research in Higher Education 46 (7): 803-30.

Cabrito, G. B. 2006. "Higher Education in Portugal: Recent Evolution, Equity, Trends and Perspectives of Future." The Journal of Finance and Management in Colleges and Universities 3 (3): 241-48.

Capelleras, J. 2005. "Attitudes of Academic Staff towards their Job and Organization: An Empirical Assessment." Tertiary Education and Management 11 (2): 147-66.

Dias, D., M. L. Machado-Taylor, R. Santiago, T. Carvalho, and S. Sousa. 2012. "Portugal: Dimensions of Academic Job Satisfaction." In Job Satisfaction Around the Academic World, edited by P. Bentley, H. Coates, I. Dobson, L. Goedegebuere, and L. Meek (The Changing Academy - The Changing Academic Profession in International Comparative Perspective, Vol. 7), 187-208. Dordrecht: Springer.

Enders, J. 1999. "Crisis? What Crisis? The Academic Professions in the 'Knowledge' Society." Higher Education 38 (1): 71-81.

GPEARI (Gabinete de Planeamento, Estratégia, Avaliação e Relações Internacionais). 2010. Docentes do Ensino Superior (2001 a 2008) [Academics in Higher Education (2001 to 2008)]. Lisbon: Gabinete de Planeamento, Estratégia, Avaliação e Relações Internacionais.

Hagedorn, L. S. 2000. "Conceptualizing Faculty Job Satisfaction: Components, Theories, and Outcomes." New Directions for Institutional Research 27 (1): 5-20.

Machado-Taylor, M. L., V. Meira Soares, J. B. Ferreira, and O. M. R. Gouveia. 2011. "What Factors of Satisfaction and Motivation Are Affecting the Development of the Academic Career in Portuguese Higher Education Institutions?" Revista de Administração Pública $(R A P) 45$ (1): 33-44.

Machado-Taylor, M. L., V. Meira Soares, and O. Gouveia. 2010. "The Study of Academic Job Satisfaction and Motivation: An Ongoing Study in Portuguese Higher Education." Global Business and Economics Anthology 2 (2): 242-46.

Meira Soares, V. 2003. The Attractiveness of the Academic Careers in Portugal. Matosinhos: Centro de Investigação de Políticas do Ensino Superior (CIPES).

Noordin, F., and K. Jusoff. 2009. "Levels of Job Satisfaction amongst Malaysian Academic Staff." Asian Social Science 5 (5): 122-28.

Platsidou, M., and G. Diamantopoulou. 2009. "Job satisfaction of Greek University Professors: Is it Affected by Demographic Factors, Academic Rank and Problems of Higher Education?" In Educating the Adult Educator: Quality Provision and Assessment in Europe, edited by G. K. Zarifis, 535-45. Conference proceedings from the ESREAReNAdET. Thessaloniki: Grafima Publications.

PORDATA. 2011. Docentes [Academics]. Lisbon: Fundação Francisco Manuel dos Santos [Francisco Manuel dos Santos Foundation]. http://www.pordata.pt/azap_runtime/?n=26\& SubThemeId $=43 \&$ Varnum $=7$

Santhapparaj, A. S., and S. S. Alam. 2005. "Job Satisfaction among Academic Staff in Private Universities in Malaysia." Journal of Social Sciences 1 (2): 72-76.

Saris, W. 2010. "Composite Scores 2008.” European Survey Research Association. http:// surveymethodology.eu/conferences/miniconference-2008/ 
Seifert, T. A., and P. D. Umbach. 2008. "The Effects of Faculty Demographic Characteristics and Disciplinary Context on Dimensions of Job Satisfaction." Research in Higher Education 49 (4): 357-81.

Silva, R. B. 1998. "Para uma Análise da Satisfação com o Trabalho" [For an Analysis of Job Satisfaction]. Sociologia, Problemas e Práticas no. 26: 149-78.

Ssesanga, K., and R. M. Garrett. 2005. "Job Satisfaction of University Academics: Perspectives from Uganda." Higher Education 50 (1): 33-56.

Stevens, P. A. 2005. The Job Satisfaction of English Academics and their Intentions to quit academe. London: National Institute of Economic and Social Research.

Teichler, U. 2009. Higher Education and the World of Work: Conceptual Frameworks, Comparative Perspectives, Empirical Findings. Rotterdam: Sense Publishers.

Verhaegen, P. 2005. "Academic Talent: Quo Vadis? Recruitment and Retention of Faculty in European Business Schools." Journal of Management Development 24 (9): 807-18.

Ward, M. E., and P. J. Sloane. 2000. "Non-Pecuniary Advantages versus Pecuniary Disadvantages: Job Satisfaction among Male and Female Academics in Scottish Universities." Scottish Journal of Political Economy 47 (3): 273-303. 